\title{
Path Dependence in Decision-Making Processes: Exploring the Impact of Complexity under Increasing Returns
}

\author{
Jochen Koch, Department of Management and Organization, European University Viadrina, Frankfurt (Oder), Germany, \\ E-mail: jkoch@euv-frankfurt-o.de \\ Martin Eisend, Department of International Marketing, European University Viadrina, Frankfurt (Oder), Germany, \\ E-mail: eisend@euv-frankfurt-o.de \\ Arne Petermann, Institute of Management, Freie Universität Berlin, Germany, E-mail: arne.petermann@fu-berlin.de
}

\begin{abstract}
The development of path-dependent processes basically refers to positive feedback in terms of increasing returns as the main driving forces of such processes. Furthermore, path dependence can be affected by context factors, such as different degrees of complexity. Up to now, it has been unclear whether and how different settings of complexity impact path-dependent processes and the probability of lock-in. In this paper we investigate the relationship between environmental complexity and path dependence by means of an experimental study. By focusing on the mode of information load and decision quality in chronological sequences, the study explores the impact of complexity on decision-making processes. The results contribute to both the development of path-dependence theory and a better understanding of decision-making behavior under conditions of positive feedback. Since previous path research has mostly applied qualitative case-study research and (to a minor part) simulations, this paper makes a further contribution by establishing an experimental approach for research on path dependence.
\end{abstract}

Keywords: Complexity; Decision-making; Path dependence; Lock-in

Manuscript received December 9, 2007, accepted by Peter Walgenbach (Management) February 3, 2009

\section{Introduction}

Path dependence is a dynamic theory assuming that initial events can increasingly restrain present and future choices. The theory originates in the historical studies of Paul David $(1985,1986)$ who explored the development of QWERTY keyboard technology. He shows how an inferior and inefficient technological standard becomes established and is maintained. Brian Arthur $(1989,1994)$ has highlighted the importance of self-reinforcing mechanisms of such path-dependent processes. The focus on selfreinforcing effects became the hallmark of pathdependence theory (Arthur 1983; David 1993; Arthur 1994; Bassanini and Dosi 2000; Ackermann 2001). These effects are the central triggering elements that drive path dependence (Sydow, Schreyögg, and Koch 2009). In addition, pathdependent processes are embedded in institutional fields and environments which may affect the path process as well (Pierson 2000). Yet little is known about the particular impact of context factors, such as ambiguity, power structures, institutional density or complexity on path-dependent processes (North 1990; Greif 1994; Thelen 2003; Pierson 2004).

\section{The unexplored context of path- dependent process}

The assumption that context matters in path-dependent processes are based on a conceptual argument. The complexity of goals, tasks, and environments in which decision makers have to operate as well as the loose and diffuse links between actions and outcomes render such settings inherently ambiguous; they are, therefore, prone to increasing returns (Pierson 2004). Context factors contribute to imper- 
fect market conditions as indicated by the existence of transaction costs. They make it difficult (if not impossible) to apply rational decision rules in terms of neoclassical theory. Pierson's argument that a context matter goes further and refers not only to the constitution of imperfect markets but to the effect that context factors impact the occurrence and intensity of self-reinforcement as well (Pierson 2004).

The literature on path dependence in economic, institutional, and political fields fails to provide clear evidence of what kind of impact relates to what kind of context factor. For instance, in the conceptualization provided by Arthur, self-reinforcing mechanisms are necessary and sufficient preconditions of path dependence, whereas context is taken for granted and, therefore, kept constant. Context is not irrelevant, but is considered a fixed premise (e.g., perfect information and the non-sponsoring rule (Arthur 1989) which frame the process). In North's conceptualization, though, context provides a necessary precondition. Without imperfect markets and transaction costs, path dependence does not occur, at least not in cases where path dependence is considered potentially inefficient: "If institutions existed in the zero-transaction-cost framework, the history would not matter; a change in relative prices or preferences would induce an immediate restructuring of institutions to adjust efficiently [...]" (North 1990: 93). Finally, Pierson places more attention on the role of contextual influences on path dependence in order to underline his central argument of political systems being more prone to path dependence than economic systems. While the discussion of differences between political and economic systems is beyond the scope of this paper, it is worthwhile emphasizing his basic assumption that also context may affect path-dependent processes. Even if this assumption may be intuitively plausible, the conceptual and empirical evidence for that issue is somewhat weak due to at least three shortcomings:

First, Pierson refers to context in a very broad and unspecified manner, mentioning a variety of factors, such as power structures, uncertainty, and unspecified preferences that describe the context of (political) decision-making. It is plausible that these factors can influence political decision-making and may lead to inertia and rigidity. Hence, context factors may provide the same explanation for outcomes such as path dependence. They could, though, pro- vide different, alternative explanations as well. There may be a correlation between both factors that influence rigidity but not necessarily a causal link.

Second, focusing on context in a broad sense makes it difficult to discern and distinguish the existence of specific causal relations between a concrete context factor and a path-dependent process. For instance, power structures and complexity are very different but nevertheless potentially interdependent concepts (e.g., power structures could be very complex and complexity may foster the emergence of informal power structures). Referring to a broad understanding of context may entail a lot of unrecognized cross effects. That may finally lead to the notfalsifiable assumption that context always matters. Third, given the fact that path-dependent processes are evolutionary and contingent, path analysis is often retrograde and provides an ex-post explanation only (see also Mahoney 2000). This is especially problematic for empirical studies based on a single or just a few cases. Referring to an opaque and highly interdependent context, it does not provide better insights into the assumed causal relationship due to the threat of ad-hoc theorizing; a given result (a path) is referred to an unspecified context which in turn is interpreted as the causal reason for that result. Another result of another case and another posteriori interpretation of the context are quite likely when following this research approach.

Considering these caveats, it seems more appropriate to opt for another research strategy by specifying and providing a clear-cut research design, focusing exclusively on very few variables and the direct measurement of their relationship. For that reason, we focus on only one particular context factor: the degree of complexity. We apply an experimental approach in order to isolate the context effect and to control for possible interferences on both the contextual level and the level of self-reinforcement.

The outline of the paper is as follows: First, we give a short introduction into path-dependence theory in order to specify our understanding of pathdependent processes. Then, we describe the context factor complexity by referring to complexity theory and psychological research on decision-making. Building on these insights, we deduce our hypothesis and research questions which are presented in the following section. Finally, we present and discuss the results of the study. 


\section{Path-dependence theory}

Path dependence is the outcome of a dynamic process that is reigned by one or more self-reinforcing mechanisms. According to previous research, we distinguish between at least six different forms of self-reinforcing mechanisms (Sydow, Schreyögg, and Koch 2005, 2009): (1) economies of scale and scope, (2) direct and indirect network externalities, (3) learning effects, (4) adaptive expectations, (5) coordination effects, and (6) complementary effects. All mechanisms share the same inherent logic. For instance, direct network externalities imply that a user's benefits from a purchased good or service increase as more users use the same good or service; purchasing and using a telephone becomes more rewarding the more users there are already using this device. Indirect externalities refer to complementary products and services accompanying a product (e.g., video stores, video recorders, etc. in the case of VHS see Cusumano, Mylonadis, and Rosenbloom 1992). Figure 1 illustrates the selfreinforcing working of both effects. not restricted at the beginning of the process, ongoing decision-making leads to restrictions. Decisionmaking systems reinforce path-building effects and at the same time the variety of choices diminish and limitations increase. They "lose sight" of other data and adopt particular decision strategies which guide them more and more in a particular direction.

It is important to note that in contrast to the common understanding of dynamic decision-making (Harvey and Fischer 2005), path-dependent processes do not require a direct and causal link between the option once chosen and the options that will still be available to the decision maker at a later point in time. In a path-dependent process the vanishing of previously available options is collateral and not necessarily a direct or causal effect of the decision path.

To sum up, paths are the emergent outcome of a self-reinforcing process resulting in a pattern of action and reflection. The development of such pattern is a non-ergodic process that becomes more and more inflexible. The concrete pattern is not

\section{Figure 1: Direct (1) and indirect (2) network effects}

$\begin{array}{lll}\text { (1) The lager the network } & \text { (2) The more complementary } \\ \text { products a network has } \\ \text { of the network }\end{array}$

All these effects lead to positive feedback loops in which at least two variables are reciprocally linked in the following way: a higher (or lower) level of one variable leads to a higher (or lower) level of the second variable which in turn leads to a higher (or lower) level of the first variable and so on.

From a dynamic decision-making perspective such a process requires a situation of repeated decisions; a decision-making system is repeatedly confronted with the same decision-making problem. Selfreinforcing mechanisms provide increasing returns to a decision-making system for each new decision. When a decision-making system follows the emerging path, the situation improves in terms of increasingly higher utility or increasingly lower costs of a repeatedly chosen option.

There are two sides to the coin, though: A path also constitutes a restriction of choice. While choices are predictable at the beginning and can lead to an inefficient outcome in the end Arthur (1989, 1994); David (2001); Pierson (2004), Sydow, Schreyögg, and Koch (2009) have re-conceptualized this process in a 3-stage model (see Figure 2).

Figure 2: The constitution of a path (Sydow, Schreyögg, and Koch 2009)

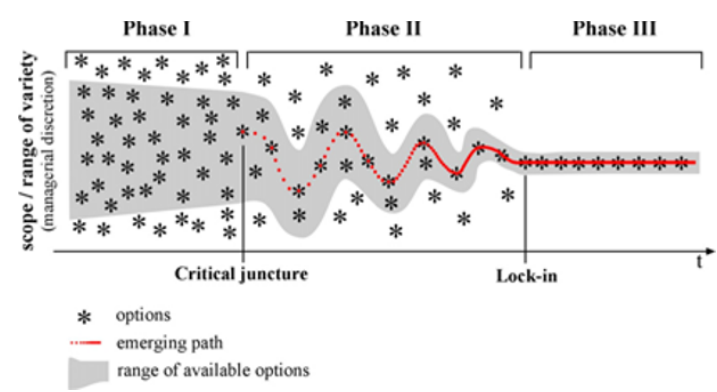


Phase I of the model is characterized by contingency. Neither is decision-making behavior undirected nor are choices fully unconstrained. History matters but in a broader sense of foregoing imprints (Boeker 1988). These imprints can lead to a narrowing of choices (indicated by the shadow), although there always remains a considerable scope of choice. Phase I ends with a critical juncture (Collier and Collier 1991), i.e., a decision and/or event leads to self-reinforcement. At that moment, a decisionmaking system enters (often unconsciously) a dynamic narrowing process triggered by positive feedback for a particular option. The system chooses the option by chance (in the sense of a small event) or intentionally (in the sense of a bigger event). The strategic intent of the choice is not necessarily the triggering of a self-reinforcing dynamic; it is rather considered a collateral outcome of strategic actions. Entering into Phase II, a set of decisions is likely to be reproduced over time. If self-reinforcing mechanisms consolidate, a pattern of reflecting and/or acting builds up that reproduces the initial decision or set of decisions. A dominant solution emerges and the process becomes more stable. Decisions taken in Phase II are nevertheless still contingent, i.e., options for alternatives still exist, although they are more and more constrained (indicated by the shadow).

With the transition to Phase III, the path becomes locked-in and the dominant pattern gains a deterministic character. The decision process is fully bound and a particular choice or decision pattern from the past has become the predominant mode. Any other alternatives are ruled out - even if they become more efficient. In contrast to technological solutions, a behavioral pattern of acting and reflecting is locked-in not only when it is completely predetermined, but also when restricted to a very narrow area of its state space (indicated by the shadow in Phase III).

The lock-in situation indicates that a pathdependent process leads to a stable and, thus, rigid outcome which is potentially inefficient and cannot be overcome by the decision-making system. The potential inefficiency is caused by a rationality shift, i.e. a change in the environment that makes another alternative more attractive. In lock-in situations the decision-making system is unable to switch to that alternative ${ }^{1}$. It is very likely that a decision-making system will not get locked-in if it becomes aware of such a change in the environment during Phase II. Then, the decision-making system will switch to the more attractive solution. Yet, there is strong evidence from different bodies of literature that such a change does not occur, if a decision-making system perceives the previous and present decisions as successful (see, for instance Miller 1993). Thus, path dependence implies a potential tradeoff between the inner rationality of a decision system and a second point of view (an outer or observer perspective) applying another form of rationality (Koch 2008). A rationality shift is defined from the observer's perspective, but whether it is noticed and how it is perceived, depends on the inner rationality of the decision-making system.

Up to now, path-dependence research has emphasized some pivotal elements that drive pathemerging processes in Phase II of the model and that eventually lead to a lock-in. As described in the introductory section, we argue that beyond these mechanisms a particular context may encourage path-dependent processes as well (Pierson 2004; see also Beyer 2005). We will now focus on complexity as such a context factor.

\section{Complexity theory, decision- making and path dependence}

According to Anderson (1999), complexity is a structural variable that "can be equated with the number of different items or elements that must be dealt with simultaneously" (Anderson 1999). Complexity refers to the relations between elements; an interconnected collection of elements is called complex "when, because of immanent constraints in the elements' connective capacity, it is no longer possible at any moment to connect every element with every other element" (Luhmann 1995: 24). Complexity also refers to decision-making systems and their ability to cope with situations of incomplete information: "Complexity [...] means being forced to select" (Luhmann 1995: 25). A complex environment requires a decision maker to reduce complex-

\footnotetext{
${ }^{1}$ This argument of potential inefficiency has provoked remarkable criticism from neoclassical researchers (Liebowitz and Margolis 1990; Liebowitz and Margolis 1994; Liebowitz and Margolis 1995; see also Regibeau 1995) because in neoclassical theory an inefficient but nevertheless rigid solution cannot occur, and if it does occur, it is always remediable.
} 
ity in order to make decisions. "People in organizations reduce a complex description of a system to a simpler one by abstracting out what is unnecessary or minor [...] compressing a longer description into a shorter one that is easier to grasp" Anderson 1999

Complexity impacts decision-making behavior in various ways: The first and most important implication is that complexity leads to a situation where the application of rational decision-making models is no longer possible or does not lead to better decisions (Simon 1987, 1990; Weick and Sutcliff 2001 As we know from the bulk of research describing and analyzing how decisions are made in organizations (Allison 1971; Cohen, March, and Olsen 1972; Pettigrew 1973; Mintzberg, Raisinghani, and Théorêt 1976; Beyer 1981; Brunsson 1982; March 1994; Crozier 1995; Staw 1997; Hendry 2000), rational decision behavior rarely occurs in the mode presumed by rational choice theory: problems are illdefined, solutions are seeking for problems, evaluations are implicit, etc. For that reason, the linear logic of rational choice theory and the assumption of rational behavior are problematic premises for both prescribing and describing decision-making in the real world.

Due to bounded rationality, a decision-making system is unable to realize and to compute any possible relation between elements in complex situations. Complexity and bounded rationality are just two sides of the same coin. The limitations of the human mind and the structure of the environment in which the mind operates are interlocked (Simon 1991; Gigerenzer and Todd 1999). Decision-making systems in real-world settings have only limited time, knowledge, and computational capacities and, therefore, complexity restrains the decision maker to draw inferences on the environment in order to reduce complexity.

In real-world settings decision makers, therefore, rely on cognitive heuristics while processing information and making decisions (Goldstein and Gigerenzer 2002). Heuristics are an appropriate strategy for reducing complexity. „The degree to which heuristics are used depends on the decision-making context" (Åstebro and Elhedhli 2006). The higher the degree of complexity the faster and the more frugal the heuristics have to be in order to work efficiently under such conditions (Rieskamp and Hoffrage 1999).

\section{Hypothesis and research questions}

The main assumption to be tested is whether complexity impacts the probability of becoming pathdependent. As shown above, this hypothesis derives directly from the path-dependence literature (Pierson 2000; 2004 In a path-dependent process successful decision-making requires the ability to detect relevant changes (a rationality shift) while positive feedback for a previously chosen option is still at work. Once a decision strategy is chosen and is reinforced by positive feedback, a decision maker is less likely to detect relevant changes in overly complex situations compared to less complex situations. The decision strategy may result in path dependence.

\section{H1: High (versus low) complexity enhances the probability that a decision maker becomes path- dependent.}

Previous research has hallmarked the role heuristics play in complex settings of decision-making and has explored which types of heuristics are applied to different tasks and environmental conditions (Tversky and Kahneman 1974; Goldstein and Gigerenzer 2002; Betsch and Haberstroh 2005; Harvey 2007). Research in the field of psychology concerning the process of sequential decision-making, the role of feedback, the internal and external reasons for staying with a previous chosen solution, and the way complexity and heuristics interact provides several explanations for path-dependent processes (Einhorn and Hogarth 1981; Hogarth, Gibbs, McKenzie, and Marquis 1991; Harvey and Fischer 2005; Jonas, Schulz-Hardt, Frey, and Thelen 2001; Sevdalis and Harvey 2007). Nevertheless and to the best of our knowledge, evidence is lacking on the functionality of heuristics under increasing returns and rationality shifts, as the central elements of path-dependent processes. Bearing in mind the purpose of this paper, we rely on very fundamental categories for capturing and analyzing such heuristics and decision-making processes. Besides testing the hypothesis of whether complexity indeed leads to path dependence, we further try to explore how complexity has an impact on path dependence. For this, we refer to basic dimensions of information which are (1) alternatives, (2) attributes, and (3) time.

Previous studies have differentiated between compensatory (attributes are outweighed by other attributes) and non-compensatory (a specific attribute 
is not outweighed by another attribute) information processing strategies. That is, whether a decision maker focuses on particular attributes or alternatives in order to come to a decision. Typically, a higher amount of alternatives or attributes leads to the increase of non-compensatory strategies where decision makers tend to focus on particular alternatives or attributes (e.g., Billings and Marcus 1983; Payne 1976; Timmermans 1993). In path-dependent models, a further dimension becomes important: time (Figure 3). A decision maker has information that refers not only to the present, but also to the past or even the future. A non-compensatory strategy in that dimension describes the focus on information related to a restricted time period. From the perspective of path-dependence theory, the investigation of a time dimension is of particular importance since path dependence is associated with a lower orientation towards the future (Miller 2002). To the best of our knowledge, this effect has not been considered in studies dealing with heuristics and sequential decision-making either and points to a research gap in that field.

\section{Figure 3: Dimensions of information retrieval in path-dependent decision- making}

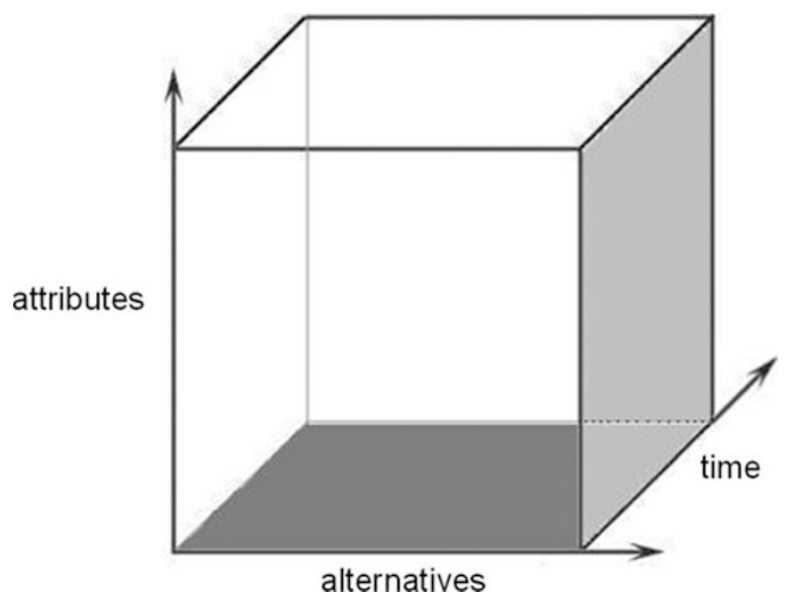

Taken together, we distinguish between three fundamental non-compensatory heuristics that we describe as a focus on alternatives $(\mathrm{FAl})^{2}$, focus on attributes (FAt) or focus on present information (FPI). The question to be answered is:

2 All abbreviations are explained in the list of acronyms in the appendix.
RQ1: Does complexity influence the (a) focus on alternatives (FAl), (b) focus on attributes (FAt) or (c) focus on present information (FPI) of a decision maker?

Provided that these heuristics are responsible for path dependence, they should work as a mediator between complexity and path dependence. We try to explore whether a complexity-driven application of these heuristics leads to path dependence.

RQ2: Does the (a) focus on alternatives (FAl), (b) focus on attributes (FAt) or (c) focus on present information (FPI) mediate the impact of complexity on path dependence such that complexity impacts (a) focus on alternatives (FAl), (b) focus on attributes (FAt) or (c) focus on present information (FPI) which in turn impact path dependence?

As we know from complexity theory and information-processing theory (Anderson 1999), complexity influences an individual decision system concerning the amount of retrieved information. In highly complex situations, it is impossible to retrieve all information available. Some authors argue that a higher level of complexity leads to a more selective search of information Ford, Schmitt, Schechtman, Hults, and Doherty 1989). When time resources for making decisions are restricted, a decision maker has to spend more time on structuring the situation (e.g., detecting what could be relevant and what could be irrelevant) and less time for retrieving information. However, a decision maker could also simply change the strategy of information retrieval in a highly complex situation and, thus, still be able to retrieve as much information as under low complexity. We formulate further research questions on the total amount of information retrieval (total information load (TIL)) as well as on its role as a mediator between complexity and path dependence.

RQ3: Does complexity influence the level of total information load (TIL)?

RQ4: Does the level of total information load (TIL) mediate the effect of complexity on path dependence such that complexity impacts TIL which in turn impacts path dependence?

Information search influences the size and quality of the consideration set of alternatives as well as the alternative that is eventually selected (Bazerman 2006). Very fast and frugal heuristics can lead to 
good decisions that even equal decisions of decision makers who can refer to a complete set of information without any computational restrictions and without time limitations (i.e., the hyper-rational decision maker can transfer complexity into simplicity) (Todd 2007). However, it is also plausible to assume that less information undermines the quality of decisions. This argument is based on the assumption that each additional piece of relevant information enhances decision quality. Higher complexity leads to less information and, therefore, to a lower level of decision quality.

As for the impact of decision quality of each decision, the impact on path dependence is ambiguous as well. At first glance, we may assume that a decision maker who is likely to make the right decision (high decision quality) does not become path-dependent as he recognizes in each situation which decision is the best. However, the idea of increasing returns introduces the dependency of decisions on previous decisions such that a decision maker may decide based on experiences of a series of former "good" decisions. He may become pathdependent as a result of positive feed-

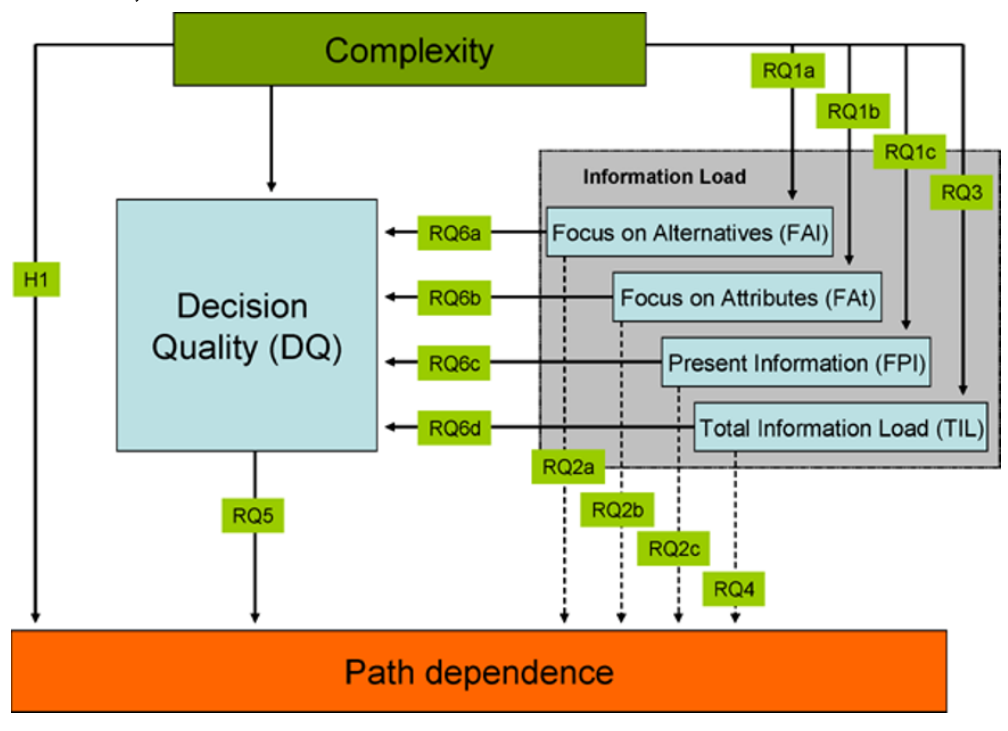
back and inertia since he keeps the formerly best decision over time, although another alternative becomes preferable. The question here is whether the likelihood of sticking with former decisions depends on complexity and finally leads to path dependence. We, therefore, try to explore the role of decision quality as a mediator between complexity and path dependence.

RQ5: Does decision quality (DQ) mediate the effect of complexity on path dependence such that complexity impacts $D Q$ which impacts the probability of path dependence.

If such a relationship exists, it is plausible to explore the heuristics mentioned above as a mediator between complexity and decision quality.

RQ6: Does the (a) focus on alternatives (FAl), (b) focus on attributes (FAt), (c) focus on present information (FPI) or (d) the level of total information load (TIL) mediate the impact of complexity on decision quality (DQ) such that complexity impacts (a) focus on alternatives (FAl), (b) focus on attributes (FAt), (c) focus on present informa- tion (FPI) or (d) the level of total information load (TIL) which in turn impact decision quality $(D Q)$ ?

Figure 4 summarizes the hypothesis and research questions and gives an overview of the relationships between the different variables to be investigated.

\section{Figure 4: Framework, hypothesis and research questions}

\section{Method}

\subsection{Overview}

We apply an experimental design in order to test the hypothesis and to explore the research questions. The experiment is based on a one-factorial betweensubjects design, manipulating the complexity of the decision environment on two levels (low vs. high complexity). Mobile service companies were used because student participants are familiar with buying decisions for mobile services. Furthermore, the purchase situation allows for different complexity settings due to varying offers of information that are common to real-life purchase situations for mobile services.

\subsection{Participants and procedure}

The experiment took place in a computer lab. We developed a software tool ("ComPad Explorer") for the purpose of the experiment. 27 students volunteered to participate in the study (13 female, 14 male students; average age 22.7 years) and were randomly assigned to the experimental groups. Stu- 
dents were advised to make several consecutive purchase decisions for a mobile service provider out of a set of four alternative providers. Information concerning the costs of the mobile services and the participants' usage behavior in the present and the near future was provided on the computer screen. For each decision, participants were given a budget of 100 units to be used up and they had up to 60 seconds to browse the provided information. If they did not make a decision within the given timeframe, the previous decision was kept.

Once a purchase decision was made, new information was provided and the participants had to decide again. Altogether, they went through this procedure 25 times, i.e., they had to make 25 consecutive decisions (later on referred to as "decision rounds").

The following information was provided in each decision round:

- the participant's use of various mobile services in the present and following four decision rounds (e.g., duration of telephone calls to fixed lines or from mobile to mobile in minutes),

- cost structure of services provided by four service providers for the present and following four decision rounds: basic fee, costs for calls to fixed
- $\quad$ lines (per minute), costs for calls from mobile to mobile (per minute), costs for international calls (per minute), costs for text messages (per unit), costs for multimedia messages (per unit), costs for WAP services (per minute). The total amount of information differs over both experimental settings (see below),

- costs for placing a new contract with another provider ("switching costs") for the present and following four decision rounds.

Information was presented along with check boxes on the computer screen. Participants first had to choose which information they would like to see and were then able to retrieve the information by clicking on a button. Requested information was provided in a pop-up. Furthermore, after each round participants received feedback in terms of their savings (budget of 100 minus the previous round's bill for mobile services). The savings from the previous round and also the sum of all previous savings were displayed. Figure 5 shows an example of the computer screen. A more detailed introductory video that explains the software tool is also available (see BuR-Website).

\section{Figure 5: Screenshot of the software interface}

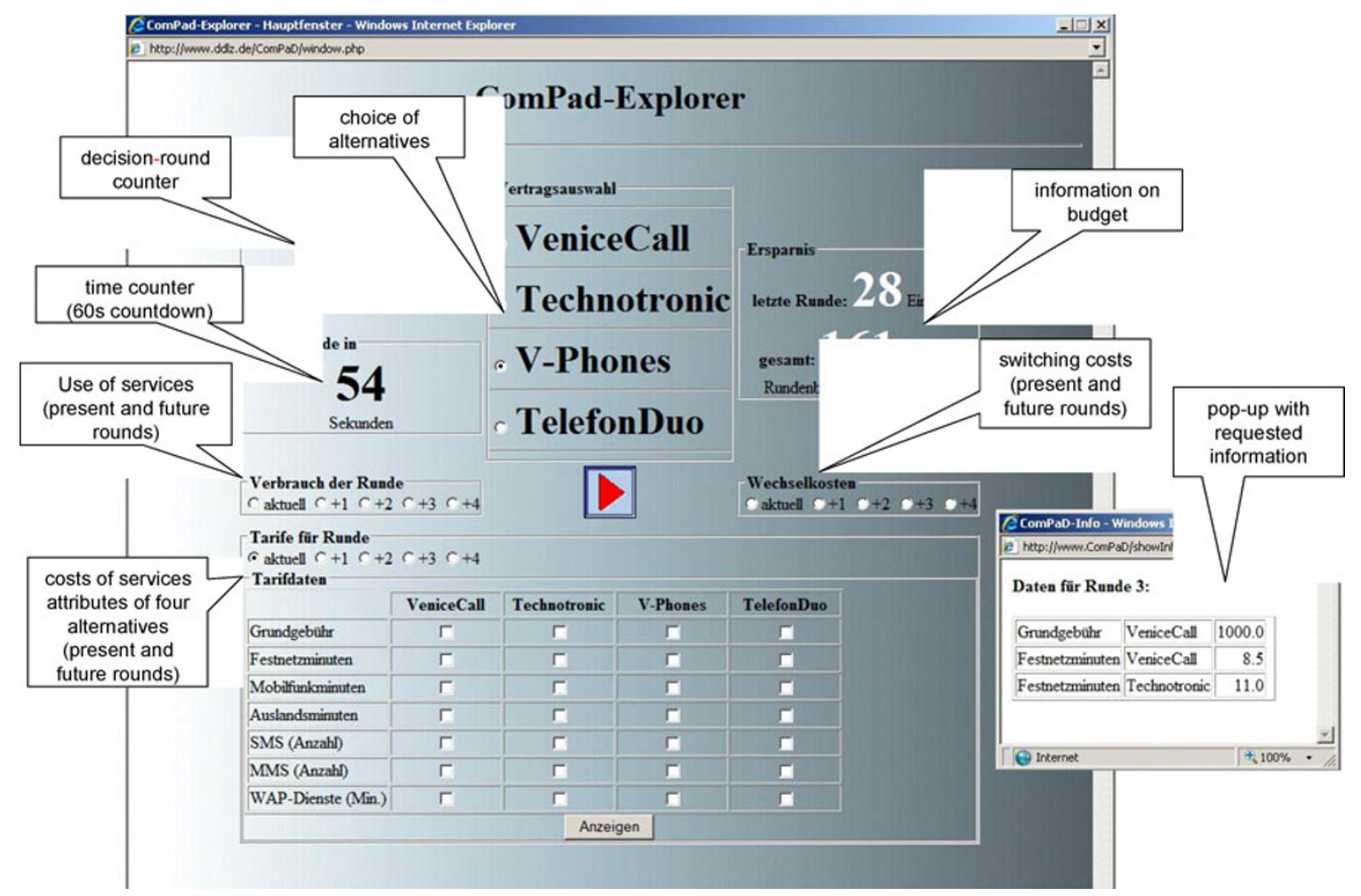


The information settings were created in order to provide an optimal decision path as well as the possibility of a lock-in, i.e., a situation where a suboptimal decision could not be changed any more due to budget restrictions. By this, we conceptualized path dependence in terms of a resource (cost)related form of lock-in. We also define an optimal decision by referring to the cost structure, i.e., an optimal decision is the one with the lowest all-over costs. Taken all costs together, a specific alternative is superior in every decision round during the course of the experiment. By providing price and demand information on the present and the next four decision rounds, participants are able to come up with an optimal decision in each round. Hence, none of the decisions is a decision under uncertainty.

In order to create a rationality shift, the superior alternative changes once in the course of the experiment. The optimal change from one alternative to another alternative is in the $17^{\text {th }}$ decision round. After that, participants could still change to the favorable alternative until the $21^{\text {st }}$ decision round. Thereafter, they could no longer shift (unless they have chosen the optimal alternative) to another alternative as the switching costs became too high to pay the bill for the switching costs with the provided budget of 100 units per round.

The change of the cost structure was mainly designed by altering three different kinds of costs: socalled "focus costs" (basic fee, costs for calls to fixed lines, and costs for calls from mobile to mobile) and so-called "hidden costs" (costs for WAP services), while the rest of the costs (for international calls, short messaging, and multimedia messaging) remained rather stable. The differentiation between "focus costs", "hidden costs", and "stable costs" is an analytical one and not obvious to the participants (i.e., the cost categories are not labeled as such).

While "focus costs" were decreasing all the time, favoring Alternative A (Figure 6), the "hidden costs" were first quite stable and after a while increasing for Alternative A, favoring Alternative B (Figure 7). The "total costs" were lowest for Alternative A until round 17 and lowest for Alternative B in the following rounds. Alternatives $\mathrm{C}$ and $\mathrm{D}$ were dummies as their "total costs" were always slightly higher (Figure 8). "Switching costs" were increasing over time (Figure 9), leading to a resource-related form of lock-in for those who stayed with Alternative A until decision round 20.

\section{Figure 6: "Focus costs"}

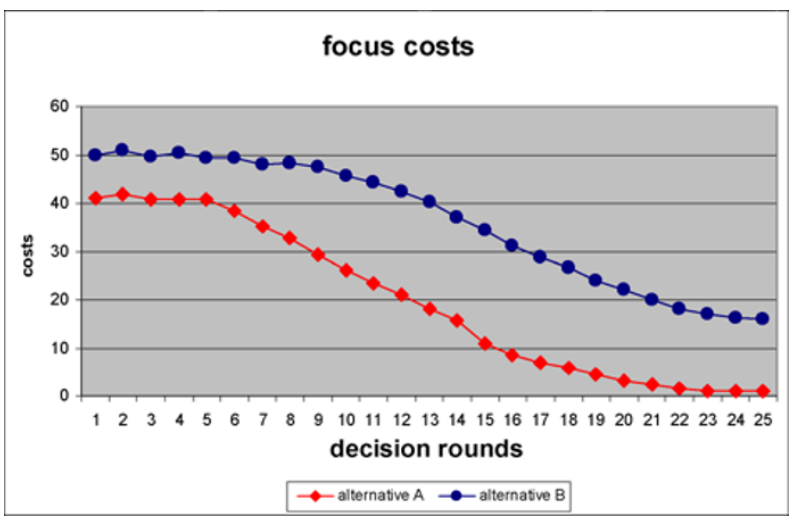

Figure 7: "Hidden costs"

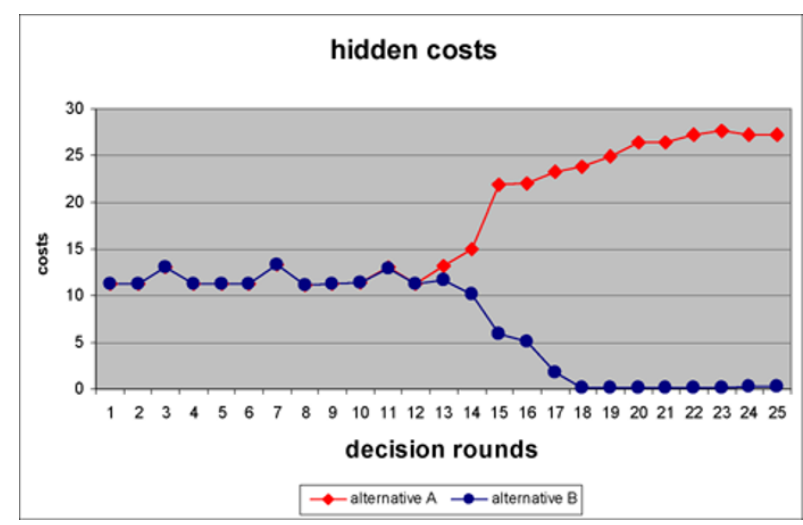

\section{Figure 8: "Total costs" ("Focus costs" and "Hidden costs")}

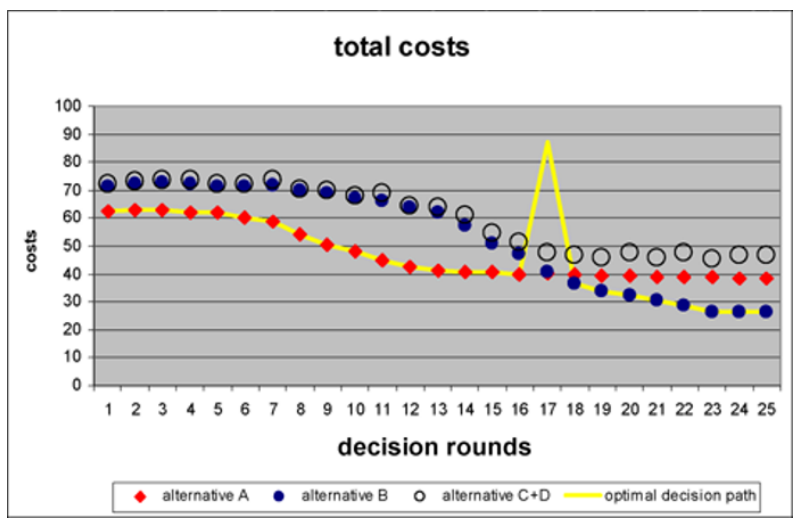


Figure 9: "Switching costs"

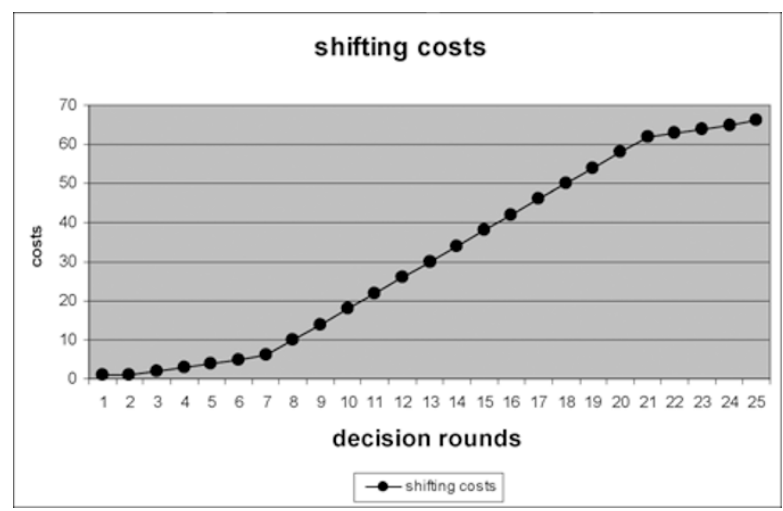

After arriving at the lab, the students were informed about the basic idea of the experiment and were advised to make several consecutive purchase decisions for a mobile service provider from a set of four alternative providers based on information given on a computer screen. Then they were instructed on how to use the software. In an initial test decision round that lasted 300 seconds they became accustomed to the software tool. Students were each given 10 euros for participating in the study. In order to ensure that participants were kept motivated to screen the given information in each round, three of the students with the best overall result (i.e., the lowest percentage of budget used) were given an additional 10 euros each after completing the study.

\subsection{Manipulation}

Complexity was manipulated by providing an information display matrix of the cost structure of the four alternatives with a varying number of service attributes. In the low-complexity (LC) setting, information was provided on costs for all calls (per minute), costs for text messaging (per unit), and costs for WAP services (per minute). In the highcomplexity (HC) setting, costs for all calls were split up into basic fee, costs for calls to fixed lines (per minute), costs for calls from mobile to mobile (per minute), and costs for international calls (per minute). Furthermore, costs for text messages (per unit) were split up into costs for two service attributes in the HC setting: costs for text messages (per unit) and costs of multimedia messages (per unit). Altogether, the LC setting provides an information display matrix of four alternatives by three attributes, while the $\mathrm{HC}$ setting provides a matrix of four alter- natives by seven attributes. Figure 10 shows the information display matrices of both settings.

\section{Figure 10: Manipulation of complexity}

\begin{tabular}{|l|c|c|c|c|}
\hline Low-complexity setting & \multicolumn{4}{|c|}{ Alternatives } \\
\hline Attributes & $\mathbf{1}$ & $\mathbf{2}$ & $\mathbf{3}$ & $\mathbf{4}$ \\
\hline Costs for calls (per minute) & & & & \\
\hline Costs for text messaging (per unit) & & & & \\
\hline Costs for WAP services (per minute) & & & & \\
\hline
\end{tabular}

\begin{tabular}{|l|l|l|l|l|}
\hline High-complexity setting & \multicolumn{4}{|c|}{ Alternatives } \\
\hline Attributes (p.m.=per minute) & $\mathbf{1}$ & $\mathbf{2}$ & $\mathbf{3}$ & $\mathbf{4}$ \\
\hline Basic fee for calls & & & & \\
\hline Costs for calls to fixed lines p.m. & & & & \\
\hline Costs for calls to mobiles p.m. & & & & \\
\hline Costs for international calls p.m. & & & & \\
\hline Costs for text messaging p.u. & & & & \\
\hline Costs for multimedia messaging p.m. & & & & \\
\hline Costs for WAP services (per minute) & & & & \\
\hline
\end{tabular}

The data was designed in a way that every alternative is based on exactly the same cost structure in both the LC and the HC setting, and the sum of the split-up costs in the HC setting were equal to the corresponding costs in the LC setting. This design implies that using the same alternative in both the $\mathrm{HC}$ and the LC setting will result in the very same "total costs".

In a pretest, 50 students were asked to evaluate the complexity of both information settings on a 9-point complexity scale. The information situation with less information was evaluated as significantly less complex than the alternative information setting $(t=2.228, p=.031)$.

It is important to note that we apply a subjective perspective of complexity. The participants in the experiment are unable to connect all relevant elements and notice all relations between elements, while an external observer (without time constraints) could do this. The rational actor provides a point of reference that helps us to establish and to 
design an optimal path. We introduce a time limit that allows us to manipulate complexity (see also the final limitations section).

\subsection{Dependent variables}

The dependent variables were path dependence, decision quality (DQ), and information retrieval in terms of focus on alternatives (FAl), focus on attributes (FAt), focus on present information (FPI), and total information load (TIL).

Path dependence was measured by a dummy variable that distinguished between choosing the optimal alternative in the last round versus choosing a non-optimal alternative. Participants who ended up with a choice for a non-optimal alternative in the last round are path-dependent since the switching costs are higher than the available budget. They are locked to the chosen alternative.

$D Q$ was measured by dummy variables, indicating whether participants were choosing the single best alternative in a decision round or not. For each participant and for decision rounds 1 to 20 (where participants were still able to choose without being locked-in) we assigned either o (wrong alternative chosen) or 1 (best alternative chosen) as value for the variable. The sum of the values of each round (i.e., the number of choices for the single best alternative in round 1 to 20) was used as a measure of decision quality.

Using log-file analysis, we were able to track the whole process of information retrieval by each participant over all 25 decision rounds. An information unit is defined as the retrieval of one piece of information, i.e., each access to a particular piece of information on the screen (e.g., WAP costs for alternative 1 in the present round).

$F A l$ and FAt are analyzed by showing how much the distribution of information load deviates from an even distribution which would represent information retrieval of a rational decision maker. For instance, an even distribution over the four alternatives would lead to $25 \%$ of units of information per alternative. Deviations from this pattern indicate that an information seeker tends to focus on information on a particular alternative at the expense of information on other alternatives. We analyze the (in) equality of distribution by calculating Gini coefficients. The coefficient is defined as a ratio with values between 0 , which corresponds to perfect equality, and 1, which corresponds to perfect inequality (Gini 1921).
FPI was measured by the ratio of information related to the present rounds to all information that was retrieved per round.

$T I L$ is the sum of all information units retrieved per round.

\section{$7 \quad$ Results}

\subsection{Hypothesis 1}

The results confirm the overall impact of complexity on path dependence. While all but one of the participants in the LC setting have switched to the favorable alternative within 25 rounds, only two participants of the $\mathrm{HC}$ setting succeeded in switching. The probability of lock-in differs significantly between both groups ( $\chi^{2}=16.385, p<.001$ ), supporting hypothesis 1.

\subsection{Research questions 1 and 2}

$F A l$ does not differ between both complexity settings $\left(G_{L C}=.039\right.$ vs. $\left.G_{H C}=.095, t=1.579, p=.127\right)$.

FAt reveals Gini coefficients that show a significant difference between both complexity settings $\left(G_{L C}=\right.$ .044 vs. $\left.G_{H C}=.249, t=5.134, p<.001\right)$ : information distribution over attributes in the LC setting is more equal than in the $\mathrm{HC}$ setting.

FPI differs between both groups considering information related to the present decision round and information related to future decision rounds. Participants in the LC situation show less FPI than participants in the $\mathrm{HC}$ setting $\left(M_{L C}=.361\right.$ vs. $M_{H C}=$ $.685 ; t=3.633, p=.001$ ).

Hence, as a response to research question 1, we found that complexity leads to an enhanced focus on attributes and on information related to the present.

A mediation test procedure that considers categorical variables was applied (Baron and Kenny 1986; MacKinnon, Fairchild, and Fritz 2007) in order to test the influence of complexity on path dependence mediated by FAl, FAt, and FPI.

The mediating effect of $F A l$ is not supported as there is no effect of complexity on $F A l$ which is a necessary condition for a mediation effect.

FAt does not function as a mediator, as the mediating variable is not significantly related to "path dependence" when both complexity and the FAt are predictors of path dependence $(b=7.314, s e=5.314$, Wald $=1.895, p=.169$ ). 
FPI does not function as a mediator to path dependence, as the mediating variable is not significantly related to "path dependence" when both complexity and FPI are predictors of path dependence $(b=2.164, s e=2.846$, Wald $=.578, p=.447)$.

Taken together, none of the heuristics works as a mediator for the direct effect of complexity on path dependence.

\subsection{Research questions 3 and 4}

The data shows an overall tendency such that participants in an LC environment retrieve more information, although the difference between both experimental groups reveals only marginal statistical significance using a two-sided test $\left(M_{L C}=\right.$ 791.583 vs. $\left.M_{H C}=610.800 ; t=1.722, p=.097\right)$. This pattern is rather consistent when comparing $T I L$ for each decision round (see Figure 11).

TIL does not function as a mediator, as the mediating variable is not significantly related to "path dependence" when both complexity and TIL are predictors of path dependence $(b=.001$, se $=.002$, Wald $=.028, p=.868$ ).

Taken together, we found only weak support for an effect of complexity on total information load which does not work as a mediator for the direct effect of complexity on path dependence.

\section{Figure 11: Total information load (TIL) per decision round in LC versus HC settings}

Note: High TIL in the first round is due to the initial test decision round that lasted 300 seconds, whereas all other rounds lasted 60 seconds.

\subsection{Research questions 5 and 6}

Complexity impacts $D Q$. Between rounds 1 and 20 (i.e., those rounds where participants are able to switch between alternatives without being lockedin), participants in the LC setting come up with the right decision more often than participants in the HC setting $\left(M_{L C}=18.250\right.$ vs. $M_{H C}=15.133$; $t=2.467, p=.021)$.

$D Q$ is a mediator for the effect of complexity on path dependence: regressing path dependence on both complexity and $D Q$ shows that complexity has a significant impact on path dependence $(b=-3.860$, $s e=1.500$, Wald $=6.624, p=.010$ ) and $D Q$ has a marginal significant impact on path dependence $(b=-.596, s e=.322$, Wald $=3.428, p=.064)$. The effect of complexity on path dependence is higher when dropping the mediator $(b=-4.270, s e=1.291$, Wald $=10.931, p=.001)$ which indicates partial mediation (Baron and Kenny 1986).

Do FAl, FAt, and FPI mediate the effect of complexity on $D Q$ ? The mediating effect for the $F A l$ is not supported as there is no direct effect of complexity on FAl.

There is no mediation effect for the FAt as the effect of the Gini coefficient in the regression model where both complexity and the Gini coefficient are used as predictors is not significant $(b=8.785$, $s e=6.202$, $t=1.416, p=.169$ ).

However, FPI which depends on complexity as shown above fully mediates the effect of complexity on $D Q$ : Regressing $D Q$ on FPI and complexity reveals a significant effect of FPI $(b=-7.186$, $s e=2.487, t=2.889, p=.008$ ) but a nonsignificant effect of complexity

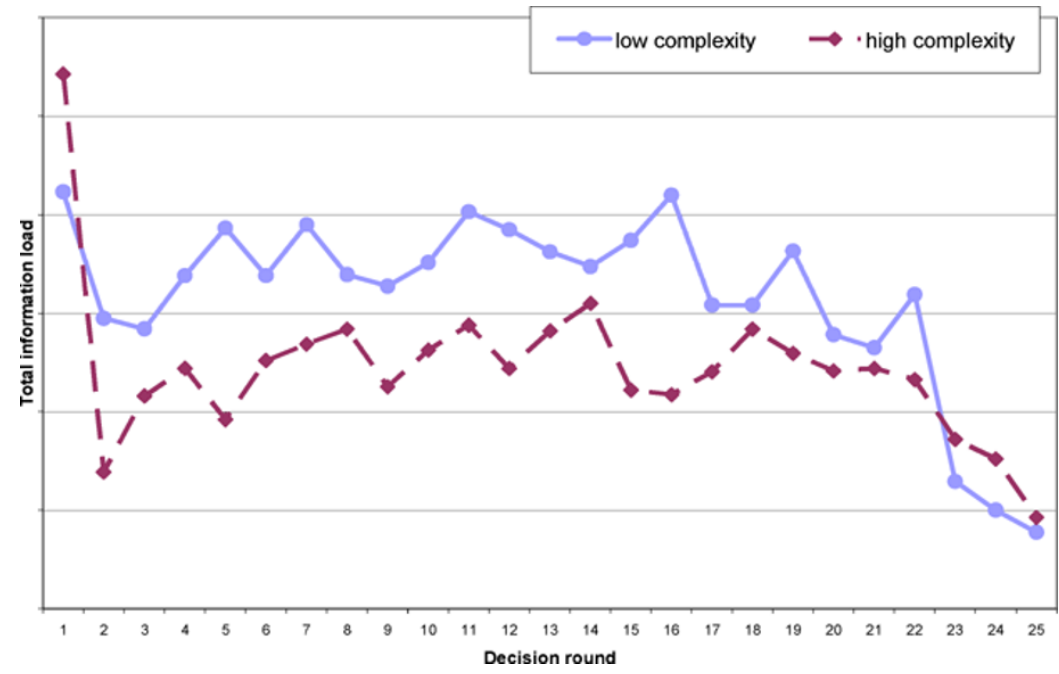
$(b=-.785$, se $=1.373, t=.572$, $p=.573)$.

Regressing $D Q$ on $T I L$ and complexity reveals marginal significant effects for both predictors (complexity: $b=$ $-2.368, s e=1.280, t=1.849, p$ $=.077$ and TIL: $b=-.004$, se = $.002, t=1.795, p=.085)$. The effect of complexity on $D Q$ is higher when dropping the mediator $(b=-3.117$, se $=$ 1.263, $t=2.467, p=.021$ ). However, such mediation effects should be interpreted with caution as complexity has 
only a marginal significant effect on $T I L$ as shown above $(t=1.722, p=.097)$.

Taken together, we found that complexity impacts decision quality which influences path dependence. The focus on present information works as a mediator such that complexity leads to increased focus on present information which in turn reduces decision quality. There is also weak support for partial mediation of total information load as a mediator between complexity and path dependence.

Figure 12 summarizes the confirmed hypothesis and the influence of the other variables which were confirmed by our analysis.

\section{Figure 12: Framework with significant relationships between variables}

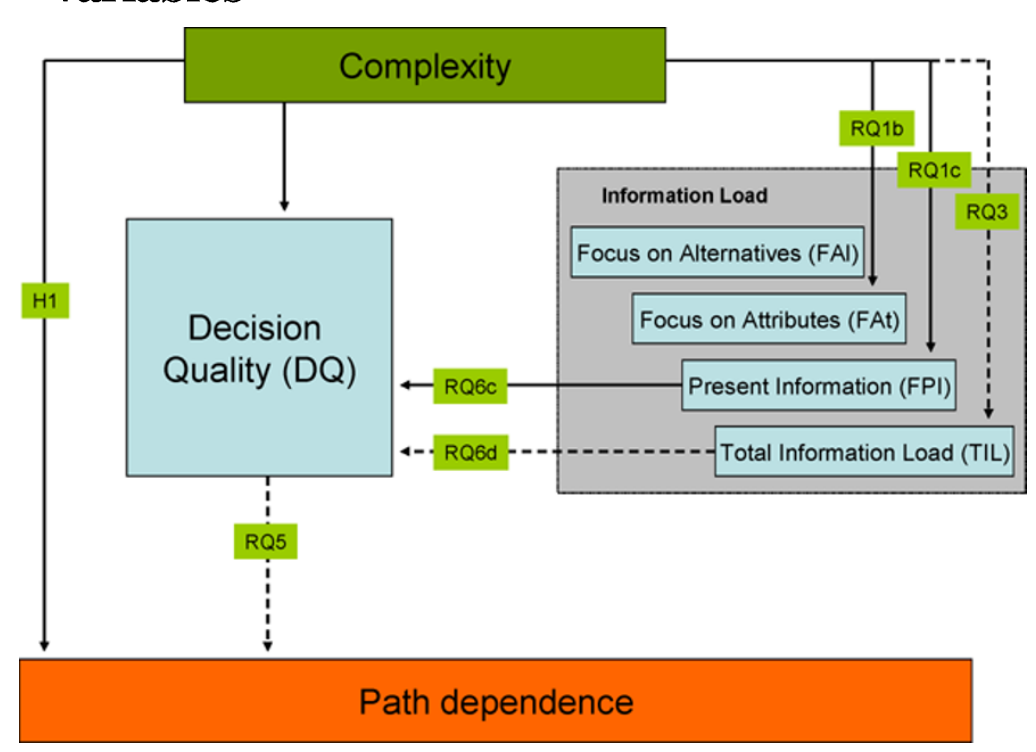

either the present or future: the proportion of information related to the present differs between decision makers under low and high complexity as decision makers in highly complex settings use a significant higher proportion of information on present rounds. As a result, decision quality depends particularly on that kind of informationretrieval behavior. Path-dependence results from poor decisions that are due to the fact that people in highly complex situations tend to neglect future developments at the expense of information on present situations. Other variations of informationretrieval behavior do not show such an effect, although the results for total information load indicate a marginal significant mediator effect. To the best of our knowledge, previous research has neglected such a "focus-on-now" heuristic. While there may be a variety of heuristics that can be successfully applied in order to reduce complexity, not all of them necessarily lead to path dependence. Up to now, the research on decision-making heuristics is focused on one-period decision-making situations and explores information-retrieval behavior along the dimensions of alternatives and attributes. Introducing a time dimension opens a new perspective for a better understanding of decisionmaking.

Furthermore, the investigation of heuristics under the condition of increasing returns provides a new subfield of research on decision-making. As we know, heuristics work as "thumb rules", sometimes also called "gut feelings". In some situations, these thumb rules may even increase the quality of decisions in comparison to decisions that are based on extensive information (Gigerenzer and Todd, 1999). The logic of path-dependent processes, however, is to trigger and to pull decision-making systems in a specific direction by providing increasing positive feedback. In our experiment participants in low versus high complex situations applied different heuristics (as indicated by their information-retrieval behavior) that resulted in varying decision quality. Hence, there seem to be different qualities of heuristics and not every heuristic is obviously able to prevent the path-dependence trap. 


\subsection{Limitations}

Although the results provide several new insights into mechanisms underlying path-dependent decision-making, the study is preliminary and has several limitations. We chose a rather arbitrary number of five decision rounds between the rationality shift and path dependence. The likelihood of switching to the superior alternative and avoiding path dependence may depend on the number of rounds between both events: with an increasing number of decision rounds, participants in highly complex settings may be able to overcome path dependence as well since the negative effect of a focus on present information is compensated over time. This has to be tested in further studies by expanding the time span between rationality shift and lock-in. However, as real decision-making usually takes place in complex environments and within restricted time frames, the assumption of a restricted number of decision rounds between rationality shift and lock-in situations seems a reasonable one in order to provide insights into real decision-making.

The manipulation of complexity follows the understanding of Anderson (1999) who defined complexity as "the number of different items or elements that must be dealt with simultaneously". Without a time restriction, the task of dealing with a high number of items or elements would be rather simple. In order to create a complex situation where participants had to deal with a high number of items or elements at the same time, the introduction of a time limit is indispensable. This manipulation bears the risk of confounding time pressure and complexity though. During the experiment, participants provided additional information on informationprocessing behavior in the form of verbal protocols. Since participants did not mention time pressure, we assume that the possible confounding effect is negligible. Still, further research should apply an experimental design that allows disentangling the effect of both factors.

Another limitation is certainly the small group size which reduces power in the analysis. This is why we were also carefully interpreting results that are described as marginally significant. Particularly, the effect from decision quality on path dependence that is a main result of our study is based on an effect size that reveals a $p$-value of .063, i.e., a value that slightly misses the usual cut-off criteria of .05. Although small group sizes are not uncommon in complex experimental designs, future research should rely on bigger samples (with group sizes of at least 20 participants) which would lead to more clear-cut results in the analysis. Nevertheless, our analysis provides a couple of significant findings in line with our assumptions as well as some interesting hints of the underlying mechanisms of pathdependent decision-making.

\subsection{Future perspectives: Towards a path- dependent decision-making model}

The lack of an impact of information-retrieval behavior (besides FPI) on path dependence is indeed a very surprising result. That could mean that the significant differences in information load do not lead to a lower information quality in terms of unrecognized relevant information ("hidden costs"). In other words, also under high complexity participants may be able to detect the relevant information even with a more focused information load on attributes and present information and a lower amount of retrieved information.

The results of an additional analysis provide preliminary support for this assumption. In the verbal protocols participants were asked to describe in a few words how they came up with a decision after each decision round. In order to test our assumption, two of the authors coded independently whether a participant mentioned the relevant costs (i.e., costs for WAP services that need to be processed in order to detect the rationality shift) or not. Coding consistency was achieved in $95.3 \%$ of the cases (i.e., each round per participant). Inconsistencies were resolved through discussion. Then we counted how often relevant costs were mentioned in rounds 11 to 25 (i.e., those rounds where the relevant costs differ between alternatives, see Figure 8). The ratio of the mentions of the relevant costs during those decision rounds does not differ between low- and high-complexity settings $\left(M_{L C}=.576\right.$ vs. $\left.M_{H C}=.433 ; t=1.322, p=.199\right)$. Hence, there seems to be no difference in recognizing the relevant costs depending on the level of complexity. However, we find a significant difference when we compare the mentions in round 17 to 20, i.e. the rounds between rationality shift and lock-in occurrence $\left(M_{L C}=.909\right.$ vs. $M_{H C}=.515 ; t=2.229, p=.040$ ). In these rounds the awareness of the relevant costs leads to dissonant information for participants who do not change to the now-better alternative. Hence, there could be a special type of dissonance-reduction strategy (Festinger, 1957) in terms of a "crowding- 
out effect" which leads to a "corruption of awareness": the recognition of relevant costs is suppressed. This effect may occur, as the development of the relevant costs and the decisions taken in the past now run into conflict. However, this explanation has to be tested further in future studies. This could be done by manipulating the strength and endurance of increasing returns.

Still, our results show that complexity has no impact on path dependence in a classical sense of "myopia" (Miller 1993; see also Tripsas and Gavetti 2000), meaning that a higher level of complexity leads directly to lower quality of information which in
- DEpt: Decision Environment in phase p and period $t$ (for $p=I$ to III and $t=1$ to $i, i+1$ to $j$, and $\mathrm{j}+1$ to $\mathrm{k}$ )

- IRP $\mathrm{pt}_{\mathrm{pt}}$ Information Retrieval and Processing in pt (for $p=I$ to III and $t=1$ to $i, i+1$ to $j$, and $j+1$ to k)

- Dpt: Decision taken in pt (for $\mathrm{p}=\mathrm{I}$ to III and $\mathrm{t}=$ 1 to $i, i+1$ to $j$, and $j+1$ to $k$ )

- Fpt: Feedback perceived in pt (for $p=$ I to III and $t=1$ to $i, i+1$ to $j$, and $j+1$ to $k$ ).

The process of path-dependent decision-making is depicted in Figure 13.

\section{Figure 13: The process of path-dependent decision-making}

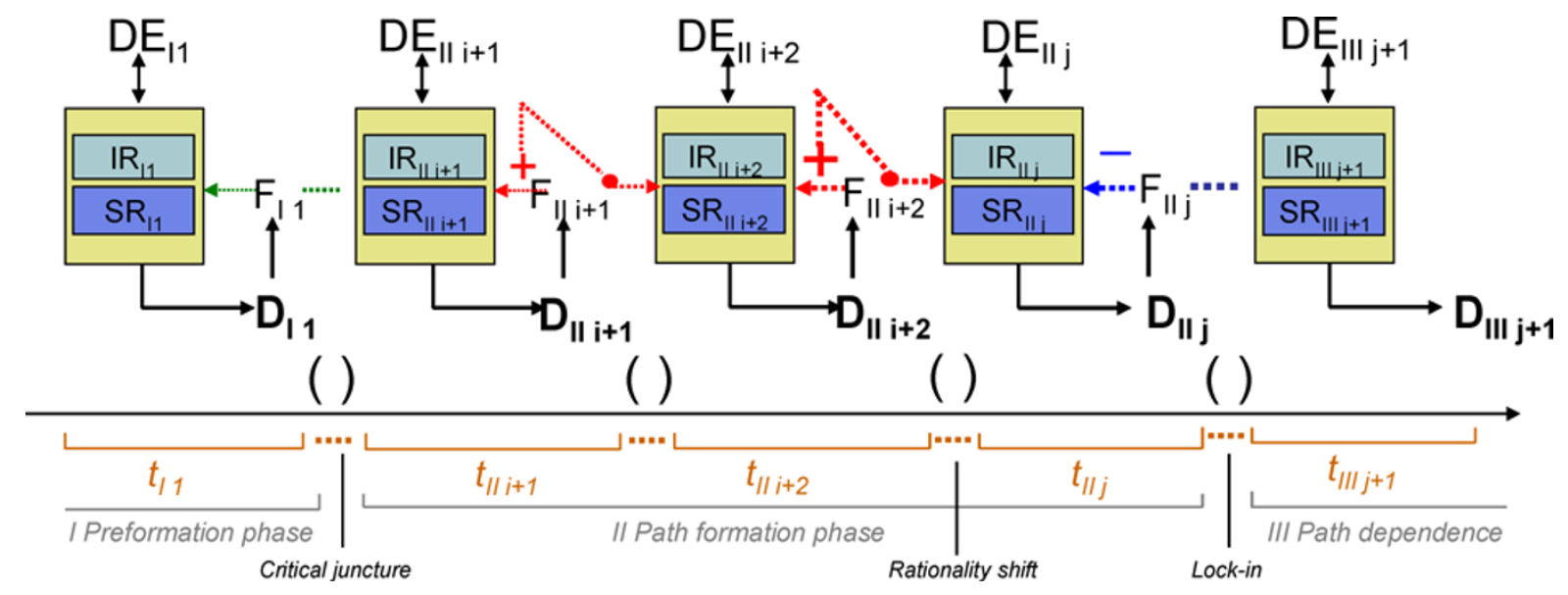

turn increases the probability of getting pathdependent. Participants in the high-complexity settings seem to apply an information load heuristic which provides sufficient information quality despite of less total information load and higher focus on information on attributes and present information. Although this phenomenon needs further proof, our results provide preliminary evidence that complexity as such could not be considered a standalone driving force for path dependence. This effect has to be further explored in future studies by manipulating complexity in settings with and without increasing returns.

As a guide for future research, we integrate these insights into the theory of path dependence and provide a path-dependent process model of decision-making as depicted in Figure 2. The following variables are used to define this process for three different phases (I: preformation phase; II: path formation phase; III: path dependence) and for sequences over time:

Note: As argued above the rationality shift (indicating an important change in the decision environment by making another choice more attractive in relation to past decisions) does not necessarily always occur in Phase III. In this model we refer to a rationality shift in Phase II which will give decision makers the possibility to anticipate and prevent path dependence.

The model indicates the assumed double effect of feedback (F) not only by confirming an already taken decision, but also by influencing future decisions since feedback impacts the whole processing of decision-making systems. Future research will have to investigate further this intriguing role of feedback in different settings of decision environments (DE). The results from our study already indicate that the effect itself is complex rather than simple. Due to the fact that path dependence occurs unintentionally, it is also very difficult to further detect and reveal the underlying cognitive processes given the threat of Hawthorne effects (Roethlisberger and Dickson 1939): only by making participants aware 
of their cognitions are they able to describe them. Such awareness, however, may lead to follow-up decisions that differ from decisions that are made when participants have not been made aware of cognitions.

\section{Appendix}

\section{List of acronyms}

$$
\begin{array}{ll}
\text { D } & \text { - Decision } \\
\text { DE } & \text { - Decision Environment } \\
\text { DQ } & \text { - Decision Quality } \\
\text { F } & \text { - Feedback } \\
\text { FAl } & \text { - Focus on a subset of the overall available } \\
& \text { set of Alternatives } \\
\text { FAt } & \begin{array}{l}
\text { Focus on a subset of the overall available } \\
\text { set of Attributes }
\end{array} \\
\text { FPI } & \text { - Focus on Present Information (ratio of } \\
& \text { present information to all retrieved infor- } \\
\text { HC } & \text { mation) }
\end{array}
$$

\section{References}

Ackermann, Rolf (2001): Pfadabhängigkeit, Institutionen und Regelreform, Mohr Siebeck: Tübingen.

Allison, Graham T. and Philip Zelikow (1971): Essence of decision: Explaining the Cuban missile crisis, Little, Brown and Co.: Boston.

Anderson, Philip, Gérard P. Cachon, and Paul H. Zipkin (1999): Complexity theory and organization science, Organization Science, 10 (3): 216-232.

Arthur, Brian W. (1983): Competing technologies and lock-in by historical events: The dynamics of allocation under increasing returns, International Institute for Applied Sciences: Laxenburg.

Arthur, Brian W. (1989): Competing technologies, increasing returns, and lock-in by historical events, The Economic Journal, 99 (394): 116-131.

Arthur, Brian W. (1994): Increasing returns and path dependency in the economy, University of Michigan Press: Ann Arbor.

Åstebro, Thomas and Samir Elhedhli (2006): The effectiveness of simple decision heuristics: Forecasting commercial success for early-stage ventures, Management Science, 52 (3): 395-409.

Baron, Reuben M. and David A. Kenny (1986): The moderatormediator variable distinction in social psychological research: Conceptual, strategic, and statistical considerations, Journal of Personality and Social Psychology, 51 (6): 1173-1182.

Bassanini, Andrea P. and Giovanni Dosi (2000): Heterogeneous agents, complementarities, and diffusion. Do increasing returns imply convergence to international technological monopolies?, in:
Domenico Dalli Gatti (ed.): Market structures, aggregation and heterogeneity, Springer: Berlin, New York, 185-206.

Bazerman, Max H. (2006): Judgment in managerial decisionmaking, Wiley and Sons: New York.

Betsch, Tilmann and Susanne Haberstroh (2005): Current research on routine decision making, in: Tilmann Betsch and Susanne Haberstroh (eds.): The routines of decision making, Lawrence Erlbaum: Mahwah, N.J., 359-376.

Beyer, Jürgen (2005): Pfadabhängigkeit ist nicht gleich Pfadabhängigkeit! Wider den impliziten Konservatismus eines gängigen Konzepts, Zeitschrift für Soziologie, 34 (1): 5-21.

Beyer, Janice. M. (1981): Ideologies, values, and decision-making in organizations, in: Paul C. Nystrom and William H. Starbuck (eds.): Handbook of organizational design, Oxford, 166-202.

Billings, Ralf S. and Simon A. Marcus (1983): Measures of compensatory and noncompensatory models of decision behavior: Process tracing versus policy capturing, Organizational Behavior and Decision Processes, 31: 331-352.

Boeker, Warren (1988): Organizational origins: Entrepreneurial and environmental imprinting at the time of founding, in: Glenn Carroll (ed.): Ecological models of organizations, Cambridge, MA: Ballinger, 33-51.

Brunsson, Nils (1982): The irrationality of action and action rationality: Decisions ideologies and organizational actions, Journal of Management Studies, 19 (1): 29-44.

Cohen, Michael D., James G. March, and Johan P. Olsen (1972): A garbage can model of organizational choice, Administrative Science Quarterly, 17: 1-25.

Collier, Ruht B. and David Collier (1991): Shaping the political arena: Critical junctures, the labor movement, and regime dynamics in Latin America, Princeton University Press: Princeton, Pennsylvania.

Crozier, Michel (1995): Bounded rationality, hyper-rationalization and the use of social science knowledge, in: Massimo Warglien and Michael Masuch (eds.): The Logic of Organizational Disorder, de Gruyter: Berlin, New York, 193-198.

Cusumano, Michael A., Yiorgos Mylonadis, and Richard S. Rosenbloom (1992): Strategic Maneuvering and Mass-Market Dynamics: The Triumph of VHS over Beta. Business History Review, 66 (1): 51-94.

David, Paul A. (1985): Clio and the economics of QWERTY, The American Economic Review, 75 (2): 332-337.

David, Paul A. (1986): Understanding the economics of QWERTY: The necessity of history, in: William N. Parker (ed.): Economic history and the modern economist, Wiley-Blackwell: Oxford, 30-49.

David, Paul A. (1993): Path-dependence and predictability in dynamic systems with local network externalities: A paradigm for historical economics, in: Dominique Foray and Christopher Freeman (eds.): Technology and the wealth of nations: The dynamics of constructed advantage, Printer Publishers: London, 208-231.

David, Paul A. (2001): Path dependence, its critics and the quest for "historical economics", in: Patrick Garrouste (ed.): Evolution and path dependence in economic ideas: Past and present, Edgar Elgar Publishing limited: Cheltenham, UK, Northampton, USA, 15-40. 
Einhorn, Hillel J. and Robin M. Hogarth (1981): Behavioral decision theory: Processes of judgement and choice, Journal of Accounting Research, 19 (1): 1-31.

Festinger, Leon (1957): A Theory of Cognitive Dissonance, Stanford University Press: Stanford.

Ford, J. Kevin, Neal Schmitt, Susan L. Schechtman, Brian M. Hults, and Mary L. Doherty (1989): Process tracing methods: Contributions, problems, and neglected research questions, Organisational Behaviour and Decision Processes, 43 (1): 75-117.

Gigerenzer, Gerd and Peter M. Todd (1999): Fast and frugal heuristics. The adaptive toolbox, in: Gerd Gigerenzer, Peter M. Todd, and ABC Research Group (eds.): Simple heuristics that makes us smart, Oxford University Press: New York, 3-34.

Gini, Corrado (1921): Measurement of inequality and incomes, The Economic Journal, 31: 124-126.

Goldstein, Daniel G. and Gerd Gigerenzer (2002): Models of ecological rationality: The recognition heuristic, Psychological Review, 109: 75-90.

Greif, Avner (1994): Cultural beliefs and the organization of society: A historical and theoretical reflection on collectivist and individualist societies, Journal of Political Economy, 102 (5): 912950.

Harvey, Nigel (2007): Use of heuristics: Insights from forecasting research, Thinking and Reasoning, 13 (1): 5-24.

Harvey, Nigel and Ilan Fischer (2005): Development of experience-based judgement and decision making: The role of outcome feedback. In: Tilmann Betsch and Susanne Haberstroh (eds.): The routines of decision making, Erlbaum: Mahwah, N. J., 119-137.

Hendry, John (2000): Strategic decision-making, discourse and strategy as social practice, Journal of Management Studies, 37 (7): 955-977.

Hogarth, Robin M., Brian J. Gibbs, Craig R. M. McKenzie, and Margaret A. Marquis (1991): Learning from feedback: Exactingness and incentives, Journal of Experimental Psychology: Learning, Memory, and Cognition, 17 (4): 734-752.

Jonas, Eva, Stefan Schulz-Hardt, Dieter Frey, and Norman Thelen (2001): Confirmation bias in sequential information search after preliminary decisions: An expansion of dissonance theoretical research on selective exposure to information, Journal of Personality and Social Psychology, 80 (4): 557-571.

Koch, Jochen (2008): Strategic paths and media management, Schmalenbach Business Review, 60: 50-73.

Liebowitz, Stan J. and Stephan E. Margolis (1990): The fable of the keys, Journal of Law an Economics, 33 (1): 1-25.

Liebowitz Stan J. and Stephan E. Margolis (1994): Network externality: An uncommon tragedy, Journal of Economic Perspectives, 8(2): 133-150.

Liebowitz, Stan J. and Stephan E. Margolis (1995): Path dependence, lock-in, and history. The Journal of Law, Economics, and Organization, 11(1): 205-226.

Luhmann, Niklas. (1995): Social systems, Stanford University Press: Stanford, CA.

MacKinnon, David P., Amanda J. Fairchild, and Matthew S. Fritz (2007): Mediation analysis, Annual Review of Psychology, 58: 593-614.
Mahoney, James (2000): Path dependence in historical sociology, Theory and Society, 29: 507-548.

March, James G. (1994): A primer on decision-making, New York.

Miller, Danny (1993): The architecture of simplicity, Academy of Management Review, 18 (1): 116-138.

Miller, Kent D. (2002): Knowledge inventories and managerial myopia, Strategic Management Journal, 23 (8): 689-706.

Mintzberg, Henry, Duru Raisinghani, and Andre Théorêt (1976): The structure of "unstructured" decision processes, Administrative Science Quarterly, 21: 246-275.

North, Douglass. C. (1990): Institutions, institutional change and economic performance, Cambridge University Press: Cambridge.

Payne, John W. (1976): Task complexity and contingent processing in decision-making: An information search and protocol analysis, Organizational Behavior and Human Performance, 16: 366-387.

Pettigrew, Andrew M. (1973): The politics of organizational decision-making, Tavistock: London.

Pierson, Paul (2000): Increasing returns, path dependence, and the study of politics, American Political Science Review, 94: 251267.

Pierson, Paul (2004): Politics in time: History, institutions, and social analysis, Princeton University Press: Princeton.

Rieskamp, Jörg and Ulrich Hoffrage (1999): When do people use simple heuristics and how can we tell? In: Gerd Gigerenzer, Peter M. Todd, and ABC Research Group (eds.): Simple heuristics that makes us smart, Oxford University Press: New York, 141-167.

Regibeau, Pierre (1995): Defending the concept of network externalities: A discussion of Liebowitz and Margolis, Research in Law and Economics, 17: 33-39.

Roethlisberger, Fritz J. and William J. Dickson (1939): Management and the worker: An account of a research program conducted by the Western Electric Company, Hawthorne Works: Chicago.

Sevdalis, Nick and Nigel Harvey (2007): "Investing" versus "investing for a reason": Context effects in investment decisions, The Journal of Behavioral Finance, 8 (3): 172-176.

Simon, Herbert A. (1987): Rational decision-making in business organizations, in: Leonard Green and John H. Kagel (eds.): $A d-$ vances in behavioral economics 1, Ablex: Norwood, 18-47.

Simon, Herbert A. (1990): Invariants of human behaviour, Annual Review of Psychology, 41: 1-19.

Simon, Herbert A. (1991): Cognitive architectures and rational analysis: Comment, in: Kurt Van Lehn (ed.): Architectures of intelligence, Erlbaum: Hillsdale, 25-39.

Staw, Barry M. (1997): The escalation of commitment: An update and appraisal, in: Zur Shapira (ed.): Organizational decisionmaking, Cambridge University Press: New York, 191-215.

Sydow, Jörg, Georg Schreyögg, and Jochen Koch (2005): Organizational paths: Path dependency and beyond, Working Paper, Freie Universität Berlin.

Sydow, Jörg, Georg Schreyögg, and Jochen Koch (2009): Organizational path dependence: Opening the black box. Academy of Management Review, 34: forthcoming. 
Thelen, Kathleen (2003): How institutions evolve. Insights from Comparative Historical Analyses, in: James Mahoney and Dietrich Rueschemeyer (eds.): Comparative Historical Analyses in the Social Sciences, Cambridge University Press: Cambridge, 208-240.

Timmermans, Danielle (1993): The impact of task complexity on information use in multi-attribute decision-making, Journal of Behavioral Decision-making, 6: 95-111.

Todd, Peter M. (2007): How much information do we need? European Journal of Operational Research, 177 (3): 1317-1332.

Tripsas, Mary and Giovanni Gavetti (200o): Capabilities, cognition, and inertia: Evidence from digital imaging, Strategic Management Journal, 21, Special Issue (10/11): 1147-1161.

Tversky, Amos and Daniel Kahneman (1974): Judgement under uncertainty: Heuristics and biases. Science, 185: 1124-1131.

Weick, Karl E. and Kathleen M. Sutcliff (2001): Managing the unexpected: Assuring high performance in an age of complexity, Jossey-Bass: San Francisco.

\section{Biographies}

Jochen Koch is Professor of Management and Organization at European University Viadrina in Frankfurt (Oder), Germany. His research interests include modern and postmodern organization theory, theories of leadership, media management, and the theory of organizational and strategic path dependence.

Martin Eisend is Professor of Marketing at European University Viadrina in Frankfurt (Oder), Germany. His research activities center on consumer behavior, marketing communication, and methods of empirical generalization.

Arne Petermann has been a Scientific Assistant at the Institute of Management at Freie Universität Berlin since 2006 after earning his master degree there. In his research he is exploring the evolution of institutional norms within organizations by means of computer simulations. Other areas of interest are complexity theory and intercultural management. $\mathrm{He}$ is teaching at the Graduate School of Business and Economics at Freie Universität Berlin. 